\title{
Hiatal hernial ulcers: clinical features and follow-up
}

\author{
E.J.S. Boyd, J.G. Penston, R.I. Russell' ${ }^{1}$ and K.G. Wormsley \\ Ninewells Hospital and Medical School, Dundee, Scotland DO1 9SY and ${ }^{1}$ Gastroenterology Unit, \\ Royal Infirmary, Glasgow, UK
}

\begin{abstract}
Summary: We describe the clinical features and therapeutic outcome in 49 patients in whom benign gastric ulceration of an hiatal hernia was demonstrated endoscopically. Hiatal hernial ulcers accounted for $10 \%$ of all benign gastric ulcers. The typical patient was an elderly female with a history of dyspepsia who was receiving non-steroidal anti-inflammatory drugs. Twenty-seven $(55 \%)$ patients had evidence of haemorrhage (acute in 15; chronic in 12) from the hiatal hernial ulcer at presentation. In 16 (33\%) patients, symptoms attributable to haemorrhage constituted the sole clinical evidence of the hiatal hernial ulcer. Acute haemorrhage from hiatal hernial ulcers was associated with non-steroidal anti-inflammatory drug (NSAID) treatment $(P<0.05)$. Chronic blood loss from hiatal hernial ulcers was associated with female gender $(P<0.005)$ but not with NSAID treatment.

Hiatal hernial ulcers healed slowly in response to medical treatment with $\mathrm{H}_{2}$-receptor antagonists (median time to healing 12 weeks). Surgical treatment may be the therapy of choice for hiatal hernial ulcers because of the high complication rate, poor response to medical therapy, and the apparent predominance of mechanical aetiological factors.
\end{abstract}

\section{Introduction}

One of the less well-known complications of diaphragmatic hiatal herniation is gastric ulceration. The ulceration may either be in the herniated portion of the stomach, or at the site of the diaphragmatic constriction - the so-called 'riding' ulcer. ${ }^{1,2}$ Descriptions of hiatal hernial ulcers are limited either to case reports of patients in whom complications have occurred, or to brief mentions in review articles concerning hiatal hernia. We have therefore undertaken a study to determine the clinical features of benign gastric ulceration occurring in relation to hiatal hernia in a large population of patients undergoing upper gastrointestinal endoscopy.

\section{Patients and methods}

The study was a retrospective evaluation of patients who underwent upper alimentary endoscopy during the period 1977-1988 in the medical gastroenterological units at Ninewells Hospital, Dundee, and Glasgow Royal Infirmary. Patients were considered eligible for inclusion in analysis if endoscopy demonstrated benign gastric ulceration in relation to an hiatal hernia (that is, an ulcer

Correspondence: K.G. Wormsley, B.Sc., M.D., F.R.C.P. Accepted: 25 March 1991 either within the hernial sac or at the isthmus caused by the diaphragm). Patients in whom erosions alone were present were excluded, since these appear to represent a separate nosological entity with different clinical features. ${ }^{3}$

The relationships between the independent variables of patient age and sex, and of treatment with non-steroidal anti-inflammatory drugs (NSAIDs), and either acute or chronic haemorrhage from hiatal hernial ulceration were evaluated using stepwise multiple regression.

\section{Results}

Sixty-nine patients in whom endoscopic examination had shown benign gastric ulceration in relation to an hiatal hernia were identified from endoscopy records. It was not possible to determine from endoscopic criteria whether the hiatal hernia was sliding or para-oesophageal in type. Case records which contained satisfactory clinical data for analysis were available from $49(71 \%)$ of patients. The age and gender distribution, and the proportion who remained alive of those patients with incomplete or untraceable records could be determined from microfilmed hospital attendance records, and were similar to those of the $71 \%$ of patients with full records. Thus, it appears likely that the study sample is representative of the total population of patients with hiatal hernial ulcers. 
Over the same period of time benign gastric ulcers at sites other than an hiatal hernia were diagnosed endoscopically in 653 patients, so that hiatal hernial ulcers account for $10 \%$ of all benign gastric ulcers.

Hiatal hernial ulcers were approximately twice as common in females as in males. Heartburn or epigastric discomfort, often of several months duration, was the most frequent complaint, but in one third of patients symptoms attributable to acute or chronic blood loss constituted the sole clinical evidence of the hiatal hernial ulcer (Table I).

\section{Complications}

Acute or chronic haemorrhage from hiatal hernial ulcers was common, and occurred at presentation in $27(55 \%)$ of patients (5 males). Acute haemorrhage (as indicated by haematemesis or melaena) at initial presentation occurred in 15 $(31 \%)$ patients. Overall, $31(65 \%)$ patients $(4$ males) had evidence of haemorrhage from an hiatal hernia ulcer at some time during the period of follow-up. Two patients died as a result of haemorrhage from an hiatal hernial ulcer (Table II).

Treatment with NSAIDs (but neither patient age nor gender) was associated with acute haemorrhage from hiatal hernial ulcers $(r=0.242$; $P<0.05)$. Female gender $(r=0.416 ; P<0.005)$ and increasing age $(r=0.266 ; P<0.05)$ were individually associated with chronic blood loss anaemia in patients with hiatal hernial ulcers, but an independent effect of age disappeared when stepwise multiple regression was applied ( $r=0.121$; not significant).

One patient in whom surgery was undertaken for
Table II Outcome during follow-up

Died (haemorrhage)

2

Surgical repair 4

Symptoms \pm recurrence $\quad 24$

Asymptomatic (no recurrence) 12*

Unknown

*Excludes those patients who underwent operation.

persisting symptoms and failure to heal during medical treatment was found at operation to have an hiatal hernial ulcer which had penetrated the diaphragm and become adherent to the liver. One patient receiving NSAIDs developed an oesophageal stricture.

\section{Response to treatment}

In 21 patients ( 11 of whom were taking NSAIDs) receiving medical therapy with $\mathrm{H}_{2}$-receptor antagonists, endoscopic data were available concerning the duration of treatment necessary to achieve ulcer healing. The median time to ulcer healing was 12 weeks, irrespective of coadministration of NSAIDs or aspirin. However, in two patients, who were both receiving continuous treatment with NSAIDs for severe rheumatoid disease, the ulcer remained unhealed after 7 and 9 months of treatment respectively.

Four patients underwent surgical treatment two for failure to heal during medical treatment (including the patient with the penetrating ulcer described above), one for oesophageal stricture formation and one for continued bleeding after

Table I Clinical features of patients with hiatal hernial ulcers

\begin{tabular}{|c|c|c|c|c|c|}
\hline Males: Females & & & \multicolumn{3}{|c|}{$17: 32$} \\
\hline Median age (range) at first diagnosis & & $\begin{array}{l}\text { Males } \\
\text { Females }\end{array}$ & \multicolumn{3}{|c|}{$\begin{array}{l}61(30-90) \text { years } \\
67(47-87) \text { years }\end{array}$} \\
\hline Median (range) duration of follow-up & & & \multicolumn{3}{|c|}{$24(0-90)$ months } \\
\hline Symptoms at presentation* & $\begin{array}{l}\text { Dyspepsia } \\
\text { Vomiting } \\
\text { Dysphagia } \\
\text { Weight loss } \\
\text { Blood loss only }\end{array}$ & & \multicolumn{3}{|c|}{$\begin{array}{c}29(59 \%) \\
9(18 \%) \\
3(6 \%) \\
4(8 \%) \\
16(33 \%)\end{array}$} \\
\hline Other endoscopic findings & $\begin{array}{l}\text { Gastric ulcer } \\
\text { Duodenal ulcer }\end{array}$ & & \multicolumn{3}{|c|}{$\begin{array}{l}2(4 \%)^{\dagger} \\
3(6 \%)^{\dagger}\end{array}$} \\
\hline $\begin{array}{l}\text { Non-steroidal anti-inflammatory drugs } \\
\text { or aspirin }\end{array}$ & & & $\begin{array}{l}\text { ales } \\
\text { males }\end{array}$ & $\begin{array}{r}\text { Yes } \\
5 \\
16\end{array}$ & $\begin{array}{l}\text { No } \\
12 \\
16\end{array}$ \\
\hline
\end{tabular}

*Some patients had more than one symptom; ${ }^{\dagger}$ one patient had both a duodenal and an incisural gastric ulcer. 
having presented with haematemesis. These patients were well and symptom-free one year after operation (Table II).

\section{Discussion}

Gastric ulcers occurring in relation to an hiatal hernia account for only $10 \%$ of cases of benign gastric ulceration. We were unable to determine the overall prevalence of ulceration in patients with hiatal hernia, but previous reports ${ }^{1,4}$ indicate that benign ulceration of the hernial sac occurs in from $4 \%$ to $30 \%$ of patients with para-oesophageal hiatal hernia (which account for $2 \%$ to $16 \%$ of all hiatal herniae), and is much less common in sliding hiatal hernia, in which the incidence is approximately $1.5 \%$. Hiatal hernial ulcers are therefore relatively uncommon, but they have considerable clinical significance because of the high proportion of haemorrhagic complications and the poor response to medical treatment which is normally very effective for other forms of benign gastric ulcer disease.

In the present study the typical patient with an hiatal hernial ulcer is an elderly female, often taking NSAIDs, and who has a previous history of gastro-oesophageal reflux or epigastric pain extending over many months. This is in agreement with previously published case reports, in which the majority of patients have been elderly females with long-standing dyspeptic symptoms. ${ }^{2,5-8}$ Although many case reports predate the introduction of NSAIDs into clinical practice, some of the patients described in the early reports were receiving treatment with aspirin. ${ }^{5-7}$ In more recent reports NSAIDs have been implicated in the pathogenesis of hiatal hernial ulcers. ${ }^{2,8,9}$ It has been reported that ulceration and haemorrhagic complications are more common in large hiatal herniae, and that small herniae become progressively larger with time. $^{10,11}$ Thus, the long duration of dyspeptic symptoms in many of our patients before clinical presentation may reflect the time required for the hernia to become sufficiently large to result in ulceration and haemorrhage.

In over half of our patients, haemorrhage (acute or chronic) was the feature which required medical advice, and in one third of patients haemorrhage was the sole presenting clinical feature. The risk of haemorrhagic complications after initial diagnosis and medical treatment was high, since $14(33 \%)$ of the 42 patients in whom follow-up data were available had episodes of haemorrhage from recurrent hiatal hernial ulceration. Haemorrhage from recurrent ulcers was acute in 10 patients $(5$ of whom had presented with acute haemorrhage) and chronic in 6 patients (two patients each presented on two separate occasions - once with acute haemorrhage and once with anaemia caused by chronic blood loss).

In the present study acute haemorrhage was more common than anaemia caused by chronic blood loss. In previously published reports the converse has been observed. ${ }^{1,5,6,12}$ This may in part be explained by the inclusion in the latter studies of patients with linear gastric erosions in the herniated stomach, since these lesions result in chronic blood loss rather than acute haemorrhage; have a less marked female preponderance; and are not associated with aspirin. ${ }^{3}$

We did not observe any instances of perforation of an hiatal hernial ulcer during follow-up of our patients, although in one patient the ulcer was found at operation to have penetrated the diaphragm and become adherent to the liver. The absence of ulcer perforation in our study may in part be the result of our method of identifying patients, since perforation requires immediate surgical intervention, rather than endoscopic examination. Although apparently rare, penetration and perforation of hiatal hernial ulcers are serious complications associated with a high mortality since they may involve the pericardium, ${ }^{13}$ myocardium, ${ }^{8,14}$ great vessels ${ }^{7,15}$ or pleural cavity, ${ }^{11,17}$ in addition to perforation into the peritoneal cavity. ${ }^{17,18}$

Hiatal hernial ulcers are slower to heal in response to standard medical therapy with $\mathrm{H}_{2}$ receptor antagonists than are benign gastric ulcers elsewhere in the stomach. The slower healing was not attributable to adverse effects of continuous treatment with NSAIDs, such as has been described during treatment of benign gastric ulcers, since median time to healing of the hiatal hernial ulcer was similar irrespective of concomitant therapy with NSAIDs. The long-term outcome of patients who did not undergo surgical treatment was also unsatisfactory since only $30 \%$ remained free of dyspeptic symptoms or ulcer recurrence.

In contrast to the unsatisfactory results which we have observed during medical therapy of hiatal hernial ulcers, surgical reduction of the hiatal hernia has been reported to give excellent results. For example, in 5 patients who underwent surgery for complications of hiatal hernial ulceration, radiological healing was observed within 17 days of operation in 4 patients, while in a fifth patient autopsy 14 days after operation revealed no visible evidence of ulceration. ${ }^{5}$ Similarly, in several other studies surgical treatment of hiatal hernia has abolished chronic blood loss, which in many cases was attributable to hiatal hernial ulceration. $1,6,12,19,20$

Hiatal hernial ulcers do not appear to be a manifestation of severe peptic ulcer disease, since the prevalence of ulceration outwith the hiatal hernia (that is, duodenal ulcer or benign gastric 
ulcer) was similar (4 to $6 \%$ ) to that expected in the general population and also similar to that observed in patients who had large hiatal herniae without hernial ulceration $(10 \%){ }^{3}$ Mechanical factors, rather than luminal aggressive factors, appear to predominate in the pathogenesis of hiatal hernial ulcers, as indicated by their site, poor therapeutic response to antisecretory drugs, and the good results of surgical restoration of the normal anatomical relationships of the stomach. The mechanical factors include trauma to the gastric mucosa at the site of diaphragmatic constriction during respiration, and ischaemia as a

\section{References}

1. Windsor, C.W.O. \& Collis, J.L. Anaemia and hiatus hernia: experience in 450 patients. Thorax 1967, 22: 73-78.

2. Richter, I.A. \& Rabin, M.S. The 'riding' ulcer. A report of 3 cases. S Afr Med J 1979, 56: 612-614.

3. Cameron, A.J. \& Higgins, J.A. Linear gastric erosion. A lesion associated with large diaphragmatic hernia and chronic blood loss anaemia. Gastroenterology 1986, 91: $338-342$.

4. Hill, L.B. \& Tobias, J.A. Para-oesophageal hernia. Arch Surg 1968, 96: 735-744.

5. Davidson, J.S. Gastric ulcer in association with hiatal hernia. Lancet 1958, ii: 729-731.

6. MacArthur, A.M. \& Wright, J.E.C. Complications of intrathoracic gastric ulcer associated with hiatus hernia $\mathrm{Br} J$ Surg 1969, 56: $161-164$.

7. Truesdale, P.E. Gastric ulcer associated with diaphragmatic hernia. $N$ Engl J Med 1932, 207: 385-390.

8. Mellet, J.S. \& Cilliers, P.H.K. Penetration of a gastric ulcer into the right ventricle. A complication of para-oesophageal hernia. S Afr Med J 1987, 72: 44-45.

9. McDonald, C.F., Walbaum, P.R., Sircus, W. \& Grant, I.W.B. Intrapleural perforation of peptic ulcer in association with diaphragmatic hernia. Br J Dis Chest 1985, 79: 196- 199.

10. Sprafka, J.L., Azad, M. \& Baronofsky, I.D. Fate of oesophageal hiatus hernia: a clinical and experimental study. Surgery 1954, 36: 519-524. result of diaphragmatic pressure on the herniated stomach. ${ }^{4-6}$

In conclusion, hiatal hernial ulcers account for $10 \%$ of benign gastric ulcers. Acute or chronic blood loss from hiatal hernial ulcers is common and acute haemorrhage is associated with NSAID treatment. Medical treatment of hiatal hernial ulcers is unsatisfactory, possibly because mechanical factors, rather than acid and pepsin, are aetiologically predominant. Surgical correction of the hiatal hernia may, therefore, be the treatment of choice in patients with hiatal hernial ulcers.

11. Flick, J.B. Hiatal hernia of the diaphragm. Surg Clin North Am 1951, 31: 1683-1692.

12. Boutelier, P., Ostovany, J. \& DeMestier, P. Les complications hémorragiques des hernies diaphragmatiques. Nouv Presse Med 1980, 9: 3071-3074.

13. Frey, E. Perforation eines Magenulkus aus einer Hiatushernie ins Perikard. Fortschr Roentgenstr 1961, 95: 852-855.

14. Nickels, J. Peptic ulcer in hiatus hernia penetrating the heart. Br J Dis Chest 1974, 68: 273-278.

15. Sabety, A.M. \& Gerard, F.P. Gastro-aortic fistula. Dis Chest 1968, 53: 783-784.

16. Ochsner, S.F. \& Ochsner, A. Hiatal hernia with gastric occlusion and intrathoracic perforation of gastric ulcer on the greater curve. Am J Surg 1958, 96: 562-564.

17. Champault, G., Michel, F. \& Patel, J.C. Les ulcères du collet des hernies hiatales: perforation en péritoine libre. Nouv Presse Med 1978, 7: 2939-2942.

18. Kleister, W.P. Catastrophic complications of hiatus hernia. Arch Surg 1952, 65: 665-672.

19. Johns, T.P.N. \& Clements, E.L. The relief of anaemia by repair of hiatus hernia. $J$ Thorac Cardiovasc Surg 1961, 41: 737-747.

20. McCormack, R.J.M. \& Walbaum, P.R. Hiatus hernia and anaemia. Coll Surg Edinb 1968, 13: 150-156. 